\title{
Does burnout affect clinical reasoning? An observational study among residents in general practice
}

\author{
Philippe Guillou', Thierry Pelaccia ${ }^{2,3}$, Marie-Frédérique Bacqué ${ }^{4}$ and Mathieu Lorenzo ${ }^{1,2^{*}}$
}

\begin{abstract}
Background: Burnout results from excessive demands at work. Caregivers suffering from burnout show a state of emotional exhaustion, leading them to distance themselves from their patients and to become less efficient in their work. While some studies have shown a negative impact of burnout on physicians' clinical reasoning, others have failed to demonstrate any such impacts. To better understand the link between clinical reasoning and burnout, we carried out a study looking for an association between burnout and clinical reasoning in a population of general practice residents.
\end{abstract}

Methods: We conducted a cross-sectional observational study among residents in general practice in 2017 and 2019. Clinical reasoning performance was assessed using a script concordance test (SCT). The Maslach Burnout Inventory for Human Services Survey (MBI-HSS) was used to determine burnout status in both original standards of Maslach's burnout inventory manual (conventional approach) and when individuals reported high emotional exhaustion in combination with high depersonalization or low personal accomplishment compared to a norm group ("emotional exhaustion +1 " approach).

Results: One hundred ninety-nine residents were included. The participants' mean SCT score was 76.44\% (95\% Cl: 75.77-77.10). In the conventional approach, 126 residents (63.31\%) had no burnout, 37 (18.59\%) had mild burnout, 23 (11.56\%) had moderate burnout, and 13 (6.53\%) had severe burnout. In the "exhaustion + 1" approach, 38 residents had a burnout status (19.10\%). We found no significant correlation between burnout status and SCT scores either for conventional or "exhaustion +1 " approaches.

Conclusions: Our data seem to indicate that burnout status has no significant impact on clinical reasoning. However, one speculation is that SCT mostly examines the clinical reasoning process's analytical dimension, whereas emotions are conventionally associated with the intuitive dimension. We think future research might aim to explore the impact of burnout on intuitive clinical reasoning processes.

Keywords: Burnout, Clinical reasoning, General practice, Medical education, Script concordance test

\footnotetext{
*Correspondence: mlorenzo@unistra.fr

'Departement of General Practice, Medicine Campus, University of

Strasbourg, 4, rue Kirschleger, 67085 Strasbourg Cedex, France

${ }^{2}$ Center for Training and Research in Health Sciences Education, Medicine

Campus, University of Strasbourg, 4, rue Kirschleger, 67085 Strasbourg Cedex,

France

Full list of author information is available at the end of the article
}

(c) The Author(s). 2021 Open Access This article is licensed under a Creative Commons Attribution 4.0 International License, which permits use, sharing, adaptation, distribution and reproduction in any medium or format, as long as you give appropriate credit to the original author(s) and the source, provide a link to the Creative Commons licence, and indicate if changes were made. The images or other third party material in this article are included in the article's Creative Commons licence, unless indicated otherwise in a credit line to the material. If material is not included in the article's Creative Commons licence and your intended use is not permitted by statutory regulation or exceeds the permitted use, you will need to obtain permission directly from the copyright holder. To view a copy of this licence, visit http://creativecommons.org/licenses/by/4.0/. The Creative Commons Public Domain Dedication waiver (http://creativecommons.org/publicdomain/zero/1.0/) applies to the data made available in this article, unless otherwise stated in a credit line to the data. 


\section{Background}

Herbert J. Freudenberger defined burnout as "becoming exhausted by making excessive demands on [ ... resources at work" [1]. The prevalence of burnout among physicians has been reported to be up to $85 \%$, and up to $75 \%$ in residents, depending on their medical specialty [2-5]. Burnout has been found, through psychometric tests, to be associated with deteriorations in attention, memory, and executive functions in the general population [6]. The effects of burnout on a physician's ability to reason have not been extensively studied, and the results are contradictory.

Clinical reasoning encompasses the range of cognitive processes necessary to evaluate and treat patients [7]; it lies "at the core of health care practice and education" [8]. Multiple clinical reasoning components can be identified: information gathering, hypothesis generation, forming a problem representation, generating a differential diagnosis, selecting a leading or working diagnosis, providing diagnostic justification, and developing a management or treatment plan [9]. One of the current main theoretical models assumes the existence of two cognitive processes commonly used by physicians to perform these steps [10, 11]: intuitive processes (system 1) and analytical processes (system 2). Both systems are jointly involved in most physicians' decisions: reasoning always starts intuitively (system 1), generating one or more possible solutions, and then the analytical system (system 2) will allow confirmation or invalidation of the relevance of these (hypotheses selection) [12].

While some studies have shown a negative impact of burnout on physicians' clinical reasoning performance [13], others have failed to demonstrate any such impact [14-16]. Residents seemed to be more susceptible to burnout effects than faculty in a study by Durning et al. [13]. Residents had different blood oxygen level-dependent (BOLD) signals detected by functional magnetic resonance when answering and reflecting upon clinical problems [13]. Higher depersonalization scores were associated with a lower BOLD signal in some areas of the brain, and higher emotional exhaustion scores were associated with stronger BOLD signals in others [13].

However, another study on pediatric residents showed no statistically significant association between burnout and harmful, nonharmful, or total errors [14]. A study on internist residents showed no difference in diagnostic and therapeutic accuracy compared with certified internists, despite significantly higher burnout scores [15]. Even more confusing, residents with high burnout scores were reported to have a small decrease in medical errors compared with burnout-free residents in a study on internal medicine residents [16].

To better understand the link between clinical reasoning and burnout, we carried out a study looking for an association between burnout status and lower clinical reasoning performance in a population of residents in general practice.

\section{Methods}

We designed a cross-sectional observational study looking for a statistical association between the scores on the French version of the Maslach Burnout InventoryHuman Services Survey (MBI-HSS) [17] and a script concordance test (SCT) [18]. We assumed that high burnout scores could be associated with a lower SCT rating. We followed the Strengthening The Reporting of OBservational studies in Epidemiology (STROBE) checklist on what should be included in an accurate and complete report of an observational study [19].

\section{Setting}

We collected data on residents' certification examinations in 2017 and 2019 at the University of Strasbourg, France. Participants were given a presentation of the study, a written consent form, and the MBI-HSS questionnaire. We informed the residents of the research goal orally and ensured the voluntary nature of their participation before the start of the examination. The SCT examination lasted $90 \mathrm{~min}$, and the residents had to stay until the end. Two of the researchers (PG and ML) were faculty for the residents.

\section{Population}

The study population consisted of general practice residents in their final year (third postgraduate year) at the University of Strasbourg. To participate, residents had to give written informed consent. Participation or nonparticipation did not influence residents' training programs or assessments.

As participants could realize that they suffered from burnout, they received the contact details of adequate support resources with the consent form before the study.

\section{Variables under consideration}

We collected information on sex, age, marital and parental status, and current residency workplace, as these variables might influence burnout and clinical reasoning, as shown in previous studies $[13,20]$.

\section{Burnout}

The MBI-HSS is the most commonly used tool to assess burnout in the medical population [5, 21]. It is a validated self-report questionnaire measuring the three dimensions of burnout: emotional exhaustion, depersonalization, and reduced personal accomplishment [22]. The MBI-HSS gives a score in each of burnout's three dimensions. Residents were asked to indicate, on a Likert scale, their 
degree of agreement with statements on a 9-item emotional exhaustion scale (e.g., "I feel I'm working too hard at my job"), a 5-item depersonalization scale (e.g., "I do not truly care what happens to some patients"), and an 8item personal accomplishment scale (e.g., "I have accomplished many worthwhile things in this job"). Each item scores from 0 to 6 on a Likert frequency scale: $0=$ never, $1=$ at least a few times a year, $2=$ at least once a month, $3=\mathrm{a}$ few times a month, $4=$ once a week, $5=\mathrm{a}$ few times a week, and $6=$ every day. We used the French version of the MBI-HSS from Mind Garden, Inc., with a license to reproduce.

We chose to use two of the main burnout cutoffs described in the literature, as there is an intense debate on the best way to define them [5, 21, 23]. No single method seems to enjoy a consensus.

First, burnout score severity cutoffs in this study were based on the original standards of Maslach's burnout inventory manual, revised in this French population [3, 17, 22, 24] (see Table 1). We will refer later to this method as the "conventional approach." Defining each dimension's cutoff remains controversial, as they may differ from one population to another [5, 21, 25, 26]. We chose these cutoffs, as they were used 10 years ago in a similar population to evaluate burnout [3].

The number of highly affected dimensions defined burnout: low with a high score in only one dimension, moderate with high scores in two dimensions, and high with high scores in all three dimensions.

Second, we analyzed the overall burnout level using the "exhaustion +1 " rule applied to MBI-HSS scores: individuals can be considered burned out when, compared to a norm group, they report high emotional exhaustion in combination with high depersonalization or low personal accomplishment [23]. In this approach, "high" means scoring in the 75th percentile or higher, while "low" refers to scoring in the 25th percentile or lower [23]. We used this method to determine burnout cutoffs, as it considers burnout more as a continuum than a predefined cutoff [21].

\section{Clinical reasoning}

Evaluation of the clinical reasoning process is a complicated task with no ideal single assessment tool [27]. Some authors consider that testing clinical reasoning in the context of uncertainty and respecting the possibility

Table $1 \mathrm{MBI}-\mathrm{HSS}$ burnout dimension cut-offs in the conventional approach

\begin{tabular}{llll}
\hline & Low & Moderate & High \\
\hline Emotional exhaustion & $\leq 17$ & $18-29$ & $\geq 30$ \\
Depersonalization & $\leq 5$ & $06-11$ & $\geq 12$ \\
Personal accomplishment & $\geq 40$ & $34-39$ & $\leq 33$ \\
\hline
\end{tabular}

of more than one good option are two core principles [28]. The script concordance test (SCT) is currently one of the most powerful tools available to assess clinical reasoning under these principles [28]. SCTs are meant to measure the degree of concordance between examinees and a reference panel of experts concerning clinical decisions and actions under uncertainty. For each item, a clinical case is presented (a vignette), containing either insufficient information to solve the clinical problem (diagnostic, treatment) or ambiguous data. A series of questions is related to the case. Each contains an option relevant to the clinical problem, followed by the presentation of new information. The examinees' task is to assess the effect this new information has on the option's status. It mostly examines the hypothesis selection stage in the clinical reasoning process [27, 29]. It is thought to explore system 2 rather than system 1 [18]. SCT is used in many curricula worldwide to evaluate clinical reasoning among pre- and postgraduate medical students.

We used SCT scores to evaluate clinical reasoning in our population. We created a 90 -item SCT on general practice [30]. We used Lubarsky et al.'s guide to develop this SCT [31] and recommendations from Dory et al. to recruit panel members and analyze scores [32]. Scores are expressed as percentages for the analysis. A pass cutoff at $60 \%$ is usually recommended. This passing cutoff is determined by the mean score of panel members (usually approximately $80 \%$ ). A score $<60 \%$ is then considered too far from what is the "good" answer to be accepted.

We chose to use universal anchors to be able to mix every type of SCT question in each vignette when wanted. One question from this SCT is presented as an example in Table 2.

\section{Statistical analysis}

For $80 \%$ power and an alpha risk of 5\%, 20 or more participants from each group (with or without burnout) were required to show a difference of 1 point or more in SCT scores.

The sample was subjected to descriptive statistical analysis. Means are presented in the results with $95 \%$ confidence intervals and the standard deviation or the minimum and maximum values.

The mean SCT scores were compared for qualitative variables of sex, marital status, and parental status using the Mann-Whitney test. We studied the statistical association between the SCT results and the quantitative age variables and the different MBI scores for each burnout dimension by calculating the Pearson correlation coefficients (Rho). Finally, we compared the means of the SCT score in the subgroups classified according to burnout severity using the Kruskal-Wallis test for the conventional 
Table 2 Example of SCT questions

\begin{tabular}{|c|c|c|c|c|}
\hline $\mathrm{N}^{\circ}$ & If you were thinking of: & $\begin{array}{l}\text { And then you were to } \\
\text { find: }\end{array}$ & $\begin{array}{l}\text { The effect of } \\
\text { information on the } \\
\text { is: }\end{array}$ & $\begin{array}{l}\text { the new } \\
\text { hypothesis }\end{array}$ \\
\hline Q1 & A right hip fracture & $\begin{array}{l}\text { No functional disability } \\
\text { on the right leg }\end{array}$ & $\begin{array}{ccc}-2 & -1 & 0 \\
\square & \square & \square\end{array}$ & $\begin{array}{ll}+1 & +2 \\
\square \quad \square\end{array}$ \\
\hline Q2 & $\begin{array}{l}\text { Prescribe a right hip X- } \\
\text { ray }\end{array}$ & $\begin{array}{l}\text { This patient walks } \\
\text { perfectly fine }\end{array}$ & $\begin{array}{ccc}-2 & -1 & 0 \\
\square & \square & \square\end{array}$ & $\begin{array}{ll}+1 & +2 \\
\square & \square\end{array}$ \\
\hline
\end{tabular}

-2 : strongly negative; -1 : negative; 0 : no effect; +1 : positive; +2 : strongly positive

burnout method and Student's t-test for the burnout "exhaustion +1 " method. Statistical analysis was performed using $\mathrm{R}$ through the GMRC Shiny Stats application and RStudio version 1.2.1335.

\section{Results}

\section{Population}

In 2017, $111(86.7 \%)$ residents agreed to participate. In 2019, 88 (66.7\%) residents agreed, for a total of 199 participants. Informed consent was obtained for all participants.

Almost two-thirds of the participants were women $(n=123)$. Most of the participants were in a relationship ( $n=139 ; 83.2 \% ; 32$ missing data) and had no children ( $n=113 ; 86.3 \%$; 68 missing data). The participants' average age was 28 [min-max: 26-42; two missing data].

\section{SCT scores}

The mean SCT score of our participants was $76.44 \%$ (95\% CI: 75.77-77.10). The minimum score was $61.30 \%$, and the maximum score was $88.96 \%(\mathrm{SD}=4.78)$.

The global SCT score of all residents for these 2 years $(n=259)$ was $76.41 \%$ (95\% CI: 75.77-77.04). There was no significant difference between the global mean scores of all residents and participants $(p=0.4738)$.

\section{Burnout assessment}

In the conventional burnout cutoff approach, 126 residents (63.31\%) had no burnout, 37 (18.59\%) had mild burnout, 23 (11.56\%) had moderate burnout, and 13 (6.53\%) had severe burnout. The mean scores were 20.88 for emotional exhaustion, 9.57 for depersonalization, and 38.52 for personal accomplishment.

Table 3 illustrates the distribution of burnout dimension scores in the conventional cutoff approach.

In the "exhaustion +1 " approach, 38 residents had a burnout status (19.10\%). High and low cutoffs for burnout dimension scores are presented in Table 4.

\section{SCT and $\mathrm{MBI}$ score association}

There was no statistically significant correlation between SCT scores and burnout status in the conventional cutoff approach $(p=0.6509)$. Details of SCT scores concerning burnout severity are presented in Table 5.

There was also no statistically significant difference between SCT scores and burnout status in the "exhaustion +1 " approach: mean SCT with burnout was $73.48 \%$ [95\% CI: 71.76-75.21] versus 72.95\% [95\% CI: 72.0173.88] without burnout; $p=0.6136$.

\section{Discussion}

\section{Comparison with the literature}

In the conventional approach, the mean burnout scores found in our study in each dimension were slightly lower than those found in a recent a literature review conducted by Erschens et al. among medical residents for emotional exhaustion (20.58 versus 22.9, respectively) and personal accomplishment (38.53 versus 35.1, respectively). However, it was higher for depersonalization (9.57 versus 8.9, respectively) [5]. Similarly, our mean burnout scores were comparable with those of a national study in France among general practice residents from 2011: 20.0 for emotional exhaustion, 9.7 for depersonalization, and 34.8 for personal accomplishment [3]. The prevalence of burnout was lower in our population than in the authors' study: $36.68 \%$ versus $48.1 \%$ [3]. We found fewer residents with burnout in the conventional approach than in a study from 2009 at the Strasbourg medical school (46\%) [24]. Our resident population seemed to suffer less from burnout than other studies.

Table 3 Repartition of burnout dimension scores in the conventional approach

\begin{tabular}{llll}
\hline & Low score & Moderate score & High score \\
\hline Emotional exhaustion & $82(41.21 \%)$ & $73(36.68 \%)$ & $44(22.11 \%)$ \\
Depersonalization & $57(28.64 \%)$ & $70(35.18 \%)$ & $82(41.21 \%)$ \\
Personal accomplishment & $94(47.24 \%)$ & $69(69.70 \%)$ & $36(18.09 \%)$ \\
\hline
\end{tabular}


Table $4 \mathrm{MBI}-\mathrm{HSS}$ burnout dimensions cut-offs in the "exhaustion +1 " approach

\begin{tabular}{llll}
\hline & Low score & Moderate score & High score \\
\hline Emotional exhaustion & $\leq 12$ & $13-27$ & $\geq 28$ \\
Depersonalization & $\leq 5$ & $5-12$ & $\geq 13$ \\
Personal accomplishment & $\geq 43$ & $34-42$ & $\leq 35$ \\
\hline
\end{tabular}

SCT scores were comparable with the values expected for such a postgraduate examination [32]. The mean SCT score for residents at the end of their formation is $75 \%$ [32].

Our results contradict our initial hypothesis, assuming that high burnout scores could be associated with a lower SCT rating. There seems to be no significant association between clinical reasoning measured by SCT and burnout within our experimental conditions.

Therefore, our results are in line with several studies that showed no negative effect of burnout on clinical reasoning in various settings [14-16]. Several factors could explain these results. In the "emotional exhaustion +1 " approach, burnout is an emotional syndrome. As emotions are known to impact clinical reasoning [33, 34], some authors argue that emotions have a greater impact on the system 1 reasoning process [35]. An SCT-specific reasoning task consisting of analyzing the impact of information on a hypothesis or an investigation option is a hypotheticaldeductive process that fosters and explores system $2[8,11]$. Consequently, one speculation regarding our results is that burnout might not affect system 2 .

However, no specific data on clinical reasoning behaviors with SCT are available. One study by Surry et al. examined clinical reasoning behaviors in a 210-item clinical-vignette MCQ test based on dual-process theory [36]. The results showed that both systems 1 and 2 processes were elicited for nearly all test questions (100 and $97.1 \%$, respectively) in a small sample of subjects [36]. Further studies are needed to explore system 1 and system 2 reasoning use during an SCT to support the assumption that SCT mostly explores system 2. Finally, our findings illustrate some of the difficulties in studying the links between clinical reasoning and burnout.

Another hypothesis would be that burnout does not affect clinical reasoning at all. Considering this would question the affective valence of intuitive reasoning.

Table 5 Comparison of SCT mean scores on burnout severity in the conventional approach

\begin{tabular}{lll}
\hline & Means SCT score (95\%CI) & $p$-value \\
\hline Burnout absence & $73.29 \%(72.32-74.29)$ & $p=0.6509$ \\
Mild burnout & $71.45 \%(69.08-73.83)$ & \\
Moderate burnout & $74.96 \%(72.43-77.49)$ & \\
Severe burnout & $71.83(70.31-73.36)$ & \\
\hline
\end{tabular}

Many authors, such as Croskerry, have argued for over a decade that emotions do impact clinical reasoning [10, 37]. As such, other studies might aim to specifically explore the impact of burnout on clinical reasoning system 1 to test the impact of burnout on clinical reasoning more specifically.

\section{Strengths and weaknesses}

Our study's main strength is its originality, as few data on the links between burnout and clinical reasoning performance are available. To the best of our knowledge, no other studies used SCT to study the links between burnout and clinical reasoning.

The use of a standardized and validated burnout questionnaire given to the whole study population has reduced subjectivity bias. The oral and written study presentation included no hypothesis but rather a broad research question to avoid influencing the participants' answers to the MBI-HSS questionnaire.

Burnout is impacted by the environment and context of the individual. We assume that being out of the real professional environment in a quiet classroom may have reduced tension for some residents. Clinical reasoning in an SCT question probably does not imply as much emotion as with a real patient. This could be another limitation of our findings. Having the subject perform a clinical reasoning task under more realistic workplace conditions could improve our research's validity.

We noticed a slight decrease in SCT scores with increased burnout levels. There might be an association that is not reflected in our study because it lacks power. A larger sample size could probably show a statistically significant difference between the groups. However, even if such a difference existed, the estimated effect size would be much lower than a standard deviation.

Measuring burnout remains challenging today. No assessment tool seems ideal, and there is much debate on the best definition of burnout [21]. The heterogeneity of research on burnout is called into question, as no less than 142 unique definitions of burnout were found in a recent review [21]. Thus, the clinical validity of burnout definitions are not certain [21]. The fourth edition of the MBI manual removed the cutoffs [38] of the classical approach and preconized the calculation of individuals' latent profiles for burnout [39]. These latent burnout profiles could be used for future research.

Likewise, assessing clinical reasoning with a single tool such as SCT may not be sufficiently valid for such a complex process [27]. Future studies on clinical reasoning and burnout may use a wide range of assessment methods, such as SCT + OSCE + direct observations + global assessments + think-aloud techniques [27].

Last, it is unclear whether nonparticipants and participants in the studied population are equivalent concerning burnout. 


\section{Conclusions}

Our data with SCT scores seem to indicate that burnout status has no significant impact on clinical reasoning among GP residents. However, burnout may either truly have no impact on clinical reasoning performance or impact system 1 processes. Overall, researching the links between burnout and clinical reasoning is complex. Further studies could explore such an impact of burnout on clinical reasoning system 1 , but this will not be an easy task. To our knowledge, there is no valid easy method capable of separating these two closely related processes. Mixed methods approaches, where qualitative studies are integrated with quantitative studies, might be a fruitful avenue for future research.

\section{Supplementary Information}

The online version contains supplementary material available at https://doi. org/10.1186/s12909-020-02457-y.

Additional file 1. All data of participants including MBI-HSS responses, SCT scores, and descriptive statistical analysis.

\section{Acknowledgments}

The authors thank Chloé Delacour and Léa Charton who helped us collect the data, François Severac and Boris Gass who gave support for statistical analysis and presentation of results. This article received support for English translation from the Maison Interuniversitaire des Sciences de I'Homme d'Alsace (MISHA) and the Excellence Initiative of the University of Strasbourg.

\section{Authors' contributions}

PG, MFB, and ML designed the study, collected data, analyzed the data, drafted the manuscript, and critically revised subsequent versions. TP helped to design the study, writing the article, and revising subsequent versions. All authors approved the final manuscript and agreed both to be personally accountable for their owns contributions and to ensure that questions related to the accuracy or integrity of any part of the work, even ones in which they were not personally involved, are appropriately investigated, resolved, and the resolution documented in the literature.

\section{Authors' information}

Philippe Guillou is MD, Med. He works as a general practitioner and faculty. He works on clinical reasoning, burnout, and learning environment. Thierry Pelaccia is MD, Ph.D. He is the director of the Centre for Training and Research in Health Sciences Education (CFRPS), Faculty of Medicine, University of Strasbourg (France), whose main field of research deals with clinical reasoning and decision-making.

Marie-Frédérique Bacqué is PsyD, Ph.D. She is director of the UR3071 laboratory Psychology Faculty, University of Strasbourg. She works in the field of death studies, psycho-oncology, burnout, and mental health. Mathieu Lorenzo is MD, Med, Ph.D. candidate. He works as a general practitioner and faculty. He works in the field of clinical reasoning assessment and virtual patients.

\section{Funding}

None.

\section{Availability of data and materials}

The dataset supporting the conclusions of this article is included in the article in Additional file 1.

\section{Ethics approval and consent to participate}

The protocol was approved by the ethical committee of the Faculty of Medicine and Dentistry, the Schools of Nursing, Physiotherapy, and Maieutics, and the Strasbourg University Hospital. We obtained informed consent to participate from all participants with a written consent form.
All methods were carried out in accordance with the STROBE guidelines.

Consent for publication

Not applicable.

\section{Competing interests}

The authors declare that they have no competing interests.

\section{Author details}

${ }^{1}$ Departement of General Practice, Medicine Campus, University of Strasbourg, 4, rue Kirschleger, 67085 Strasbourg Cedex, France. ${ }^{2}$ Center for Training and Research in Health Sciences Education, Medicine Campus, University of Strasbourg, 4, rue Kirschleger, 67085 Strasbourg Cedex, France. ${ }^{3}$ Prehospital Emergency Care Service, Strasbourg University Hospital, University of Strasbourg, 1, place de l'hôpital, BP 426, 67091 Strasbourg Cedex, France. ${ }^{4}$ EA3071, Psychology Faculty, University of Strasbourg, 12, rue Goethe, 67000 Strasbourg, France.

Received: 11 September 2020 Accepted: 11 December 2020

Published online: 07 January 2021

\section{References}

1. Freudenberger HJ. Staff Burn-Out. J Soc Issues. 1974;30(1):159-65.

2. Ishak WW, Lederer S, Mandili C, Nikravesh R, Seligman L, Vasa M, et al. Burnout during residency training: a literature review. J Grad Med Educ. 2009;1(2):236-42.

3. Galam E, Komly V, Tourneur AL, Jund J. Burnout among French GPS in training: a cross-sectional study. Br J Gen Pract. 2013;63(608):e217.

4. Dyrbye L, Shanafelt T. A narrative review on burnout experienced by medical students and residents. Med Educ. 2016;50(1):132-49.

5. Erschens R, Keifenheim KE, Herrmann-Werner A, Loda T, Schwille-Kiuntke J, Bugaj TJ, et al. Professional burnout among medical students: systematic literature review and meta-analysis. Med Teach. 2019;41(2):172-83.

6. Deligkaris P, Panagopoulou E, Montgomery AJ, Masoura E. Job burnout and cognitive functioning: a systematic review. Work Stress. 2014;28(2):107-23.

7. Barrows HS, Tamblyn RM. Problem-based learning: an approach to medical education. New York: Springer Publishing Company; 1980. p. 225.

8. Higgs J, Jensen GM, Loftus S, Christensen N. Clinical reasoning in the health professions. Edinburgh: ElsevierHealth Sciences; 2018. p. 532.

9. Gruppen LD, Frohna AZ. Clinical Reasoning. In: Norman GR, van der Vleuten CPM, Newble DI, DHJM D, Mann KV, Rothman A, et al., editors. International Handbook of Research in Medical Education. Dordrecht: Springer Netherlands; 2002. p. 205-30. Available from: http://link.springer.com/10.1 007/978-94-010-0462-6_8. [cited 2019 Jul 14].

10. Croskerry P. A universal model of diagnostic reasoning. Acad Med J Assoc Am Med Coll. 2009;84(8):1022-8.

11. Pelaccia T, Tardif J, Triby E, Charlin B. An analysis of clinical reasoning through a recent and comprehensive approach: the dual-process theory. Med Educ Online. 2011;16:5890. https://doi.org/10.3402/meo.v16i0.5890.

12. Hogarth RM. Deciding analytically or trusting your intuition? The advantages and disadvantages of analytic and intuitive thought. In: The routines of decision making. 1st ed. New York: Psychology Press; 2004. p. 16

13. Durning SJ, Costanzo M, Artino AR, Dyrbye LN, Beckman TJ, Schuwirth L, et al. Functional neuroimaging correlates of burnout among internal medicine residents and faculty members. Front Psychiatry. 2013;4:131. https://doi.org/10.3389/fpsyt.2013.00131.

14. Brunsberg KA, Landrigan CP, Garcia BM, Petty CR, Sectish TC, Simpkin AL, et al. Association of pediatric resident physician depression and burnout with harmful medical errors on inpatient services. Acad Med. 2019;94(8): 1150-6.

15. McBee E, Ratcliffe T, Picho K, Schuwirth L, Artino AR, Yepes-Rios AM, et al. Contextual factors and clinical reasoning: differences in diagnostic and therapeutic reasoning in board certified versus resident physicians. BMC Med Educ. 2017;17(1):211

16. Kwah J, Weintraub J, Fallar R, Ripp J. The effect of burnout on medical errors and professionalism in first-year internal medicine residents. J Grad Med Educ. 2016;8(4):597-600.

17. Maslach C, Jackson SE, Leiter MP. Maslach burnout inventory manual. 3rd. Palo Alto: Consulting Psychologists Press; 1996. p. 191-218. 
18. Charlin B, Roy L, Brailovsky C, Goulet F, van der Vleuten C. The script concordance test: a tool to assess the reflective clinician. Teach Learn Med. 2000;12(4):189-95.

19. von Elm E, Altman DG, Egger M, Pocock SJ, Gøtzsche PC, Vandenbroucke $J P$, et al. The strengthening the reporting of observational studies in epidemiology (STROBE) statement: guidelines for reporting observational studies. Ann Intern Med. 2007;147(8):573-7.

20. Richter A, Kostova P, Harth V, Wegner R. Children, care, career - a crosssectional study on the risk of burnout among German hospital physicians at different career stages. J Occup Med Toxicol Lond Engl. 2014;9(1):41.

21. Rotenstein LS, Torre M, Ramos MA, Rosales RC, Guille C, Sen S, et al. Prevalence of burnout among physicians: a systematic review. JAMA. 2018; 320(11):1131-50

22. Maslach C, Jackson SE. The measurement of experienced burnout. J Organ Behav. 1981;2(2):99-113.

23. Brenninkmeijer V, VanYperen N. How to conduct research on burnout: advantages and disadvantages of a unidimensional approach in burnout research. Occup Environ Med. 2003;60(suppl 1):i16-20.

24. Ernst $M$. Le syndrome de burnout des internes en médecine générale à la Faculté de Médecine de Strasbourg: prévalence et analyse d'entretiens. France: Université de Strasbourg. Faculté de médecine; 2009.

25. Schaufeli WB, Van Dierendonck D. A cautionary note about the crossnational and clinical validity of cut-off points for the Maslach burnout inventory. Psychol Rep. 1995;76(3 Pt 2):1083-90.

26. Kovess-Masfety V, Saunder L. Le burnout : historique, mesures et controverses. Arch Mal Prof Environ. 2017;78(1):16-23.

27. Daniel M, Rencic J, Durning SJ, Holmboe E, Santen SA, Lang V, et al. Clinical reasoning assessment methods: a scoping review and practical guidance. Acad Med. 2019;94(6):902.

28. Cooke S, Lemay J-F. Transforming medical assessment: integrating uncertainty into the evaluation of clinical reasoning in medical education. Acad Med. 2017;92(6):746-51.

29. Charlin B, Gagnon R, Pelletier J, Coletti M, Abi-Rizk G, Nasr C, et al. Assessment of clinical reasoning in the context of uncertainty: the effect of variability within the reference panel. Med Educ. 2006:40(9):848-54.

30. Attali C, Huez J-F, Valette T, Lehr-Drylewicz A-M. Les grandes familles de situations cliniques. Exercer. 2013;24(108):165-9.

31. Lubarsky S, Dory V, Duggan P, Gagnon R, Charlin B. Script concordance testing: from theory to practice: AMEE guide no. 75. Med Teach. 2013;35(3): 184-93.

32. Dory V, Gagnon R, Vanpee D, Charlin B. How to construct and implement script concordance tests: insights from a systematic review. Med Educ. 2012; 46(6):552-63.

33. McConnell MM, Eva KW. The role of emotion in the learning and transfer of clinical skills and knowledge. Acad Med J Assoc Am Med Coll. 2012;87(10): 1316-22.

34. Kozlowski D, Hutchinson M, Hurley J, Rowley J, Sutherland J. The role of emotion in clinical decision making: an integrative literature review. BMC Med Educ. 2017;17(1):255

35. Croskerry P, Norman G. Overconfidence in clinical decision making. Am J Med. 2008;121(5 Suppl):S24-9.

36. Surry LT, Torre $D$, Durning $S$ J. Exploring examinee behaviours as validity evidence for multiple-choice question examinations. Med Educ. 2017;51(10): 1075-85.

37. Croskerry P, Abbass AA, Wu AW. How doctors feel: affective issues in patients' safety. Lancet Lond Engl. 2008;372(9645):1205-6.

38. Mind Garden. The Problem with Cut-Offs for theMaslach Burnout Inventory. Available from: https://www.mindgarden.com/documents/MBI-CutoffCaveat.pdf. Accessed 11 Nov 2020.

39. Leiter MP, Maslach C. Latent burnout profiles: a new approach to understanding the burnout experience. Burn Res. 2016;3(4):89-100.

\section{Publisher's Note}

Springer Nature remains neutral with regard to jurisdictional claims in published maps and institutional affiliations.

\section{Ready to submit your research? Choose BMC and benefit from:}

- fast, convenient online submission

- thorough peer review by experienced researchers in your field

- rapid publication on acceptance

- support for research data, including large and complex data types

- gold Open Access which fosters wider collaboration and increased citations

- maximum visibility for your research: over $100 \mathrm{M}$ website views per year

At BMC, research is always in progress.

Learn more biomedcentral.com/submissions 